\title{
Outcomes and anticoagulation use for elderly patients that present with an Acute Hip Fracture: multi-centre, retrospective analysis.
}

\section{Katherine Creeper ${ }^{1,2}$, Andrew Stafford ${ }^{3}$, Sophie Reynolds ${ }^{4}$, Sapna Samida ${ }^{4}$, Stephanie P' $\mathrm{Ng}^{2,5}$, Denise Glennon $^{6}$, Hannah Seymour ${ }^{7}$ and Carolyn Grove ${ }^{1,2,8}$}

1. Sir Charles Gairdner Hospital, Haematology Department, Nedlands, Western Australia

2. PathWest Laboratory Medicine, Nedlands, Western Australia

3. Curtin University of Technology, School of Pharmacy and Biomedical Sciences, Bentley, Western Australia

4. Royal Perth Hospital, Department of Geriatric Medicine, Perth, Western Australia

5. Fiona Stanley Hospital, Department of Haematology, Murdoch, Western Australia

6. Sir Charles Gairdner Hospital, Department of Rehabilitation and Aged Care, Nedlands, Western Australia

7. Fiona Stanley Hospital, Department of Geriatrics and Aged Care, Murdoch, Western Australia

8. University of Western Australia, School of Medicine and Pharmacology, Nedlands, Western Australia

All authors declare no competing interests. No external funding was provided.

\author{
All correspondence should be directed to: \\ Dr Katherine Creeper \\ PO BOX 306 \\ Floreat WA 6014 \\ kcreeper@iinet.net.au \\ +61412288371
}

This article has been accepted for publication and undergone full peer review but has not been through the copyediting, typesetting, pagination and proofreading process which may lead to differences between this version and the Version of Record. Please cite this article as doi: $10.1111 /$ imj.15007 


\section{Abstract \\ Background}

Hip fractures are a common problem and corrective surgery is recommended within 24hrs. However, most perioperative direct oral anticoagulant (DOAC) guidelines suggest a washout period of 48 hours before major surgery. There is limited data on utility of drug levels.

\section{Objective}

To investigate the effect of DOAC therapy on time to surgery and patient outcomes, and to explore the impact of different pre-operative protocols on surgical delay.

\section{Methods}

A multi-centre, retrospective analysis of all adult patients that presented with acute hip fracture at three tertiary hospitals in Perth, Western Australia was performed. Data was collated from the West Australian hip fracture registry and electronic records. Time to theatre, DOAC levels, bleeding and transfusion rates were compared between sites.

\section{Results}

Of 1240 hip fracture patients 145 (11.8\%) were on anticoagulation, with more patients taking a DOAC than warfarin. The time to surgery was significantly longer for those on a DOAC compared to those on warfarin $(\mathrm{P}=$ 0.003). There was no difference in bleeding, transfusion requirement or 30-day mortality in patients taking a DOAC compared to those on warfarin. 58 patients (70.7\%) had a DOAC level prior to surgery. Of 25 patients who had a level performed within 12 hours of presentation $13(52 \%)$ had result of $\leq 50 \mathrm{ng} / \mathrm{mL}$. Outcomes were similar between sites.

\section{Conclusion}


People on DOAC treatment had a significant delay before corrective surgery compared to those on warfarin. The frequent finding of early DOAC levels $<50 \mathrm{ng} / \mathrm{mL}$ suggests this delay may be unnecessary in a significant proportion of patients.

\section{Key Words}

Anticoagulation, Elderly, Hip, Fracture, Outcomes 


\section{Introduction}

With the aging population an increasing number of patients are being treated for hip fractures. Approximately 20,000 people across Australia fracture their hip each year. Consequently, hip fractures represent a substantial burden to individuals, their family and the health care system.

Fractures of the proximal femur are associated with approximately 5-10\% mortality within the first 30 days ${ }^{1}$. Time to surgery is of particular importance in terms of both early and late mortality ${ }^{1-3}$. Early surgery $(<24$ hours) is associated with a reduction in 30-day mortality. Shorter time to surgery allows for earlier mobilisation and prevents associated complications including sepsis and venous thromboembolism ${ }^{4}$. The current Australian hip fracture clinical care standard recommends surgery within 48 hours of presentation, which was achieved in $76 \%$ of patients Australia wide in $2018{ }^{5}$. The reason given for delay $>48$ hours was 'issues with anticoagulation' in $17 \%$ of cases, making this a significant modifiable reason. Western Australia was the second-best performing state in time to surgery with median of 24 and average of 31 hours after presentation ${ }^{6}$.

The introduction of the direct acting oral anticoagulants (DOACs) rivaroxaban, apixaban and dabigatran onto the Australian national formulary in 2013 has shifted anticoagulant prescribing practices. Warfarin is prescribed less frequently, and the use of these novel agents is increasing ${ }^{7}$. In contrast to the vitamin $\mathrm{K}$ antagonists where standardised drug levels exist, there is a lack of consensus on the role of DOAC levels in the peri-operative setting. Reported guidelines incorporate a bleeding assessment utilising knowledge of time of last dose, drug dosage, renal function, expected clearance and planned surgical procedure ${ }^{8-10}$. Minimal data exists on the utility of DOAC levels in this setting. Operative correction of femur fractures is rarely life threatening and as therefore emergency antidote therapy is not recommended.

In the absence of international consensus guidelines, the three tertiary hospitals in Western Australia independently developed peri-operative protocols for the management of hip fracture patients on anticoagulation. Hospital A recommends drug levels and proceeds to theatre if the DOAC level is $<50 \mathrm{ng} / \mathrm{mL}$, regardless of agent. Hospital B performs a bleeding assessment utilising DOAC dose, time of last dose and projected clearance based on renal function, and does not recommend DOAC levels. Hospital C utilises both bleeding assessment (as 
detailed above) and DOAC level. A baseline DOAC level $<30 \mathrm{ng} / \mathrm{mL}$ was considered safe for surgery, with a recommendation to repeat the DOAC level before proceeding if this was incongruent with the expected result. Otherwise the DOAC level along with renal function was used to guide projected clearance and plan surgical timing.

We set out to investigate the effect of DOAC therapy on time to surgery and patient outcomes, and to explore the impact of different protocols on surgical delay.

\section{Methods}

\subsection{Study Design and Participants}

A multi-centre, retrospective analysis of chart and laboratory data for all adult patients that presented with an acute hip fracture at the three tertiary hospitals in Perth, Western Australia between $1^{\text {st }}$ January 2017 and $31^{\text {st }}$ December 2017 was performed. Patients who did not undergo operative management were excluded. Ethics approval for the multi-site analysis was provided through the Western Australian Department of Health process.

\subsection{Study Population}

Patients were identified using the Australia and New Zealand Hip Fracture registry database. This is a clinician led, web-based database capturing all patients who present with hip fracture. It is used for audits on acute care and secondary fracture prevention. From this database, all patients who experienced a hip fracture and were treated in the three tertiary hospitals within Western Australia between $1^{\text {st }}$ January 2017 to $31^{\text {st }}$ December 2017 were identified.

\subsection{Variables}

Patient demographics (age, gender), time to theatre (from first presentation at any hospital), and 30-day mortality data were obtained. Baseline anticoagulant and antiplatelet use, and pre- and post-operative haemoglobin levels were obtained from hospital health information systems. 
Where patients were taking a DOAC drug levels were recorded (when performed). Results were then grouped into those who had levels $\leq 30 \mathrm{ng} / \mathrm{mL}$, those who had levels $>30$ and $\leq 50 \mathrm{ng} / \mathrm{mL}$ and those who had levels $>50$ ng/mL. These cut off values were based upon pharmacokinetic data of peak, trough and elimination half-lives ${ }^{11}$.

The time to theatre was calculated from time of first presentation to any hospital (regardless of location and ability to perform correctional surgery) to the time of operation. To objectively quantify bleeding across the different groups the change in haemoglobin $(\mathrm{Hb})(\mathrm{g} / \mathrm{L})$ was used. This was defined as the difference between the maximum recorded $\mathrm{Hb}$ level up to 48 hours pre-operatively to the minimum level recorded within 72 hours post-operatively. Peri-operative packed red blood cell (PRBC) transfusion requirements were defined across the same time interval, with these data obtained from the Australian Red Cross Blood service. To avoid skewed data from large bleeds requiring multiple units of PRBCs, the number of patients with a fracture requiring a transfusion was analysed in preference to the total number of PRBC units.

\subsection{Statistical Analysis}

All analyses were done in samples stratified by hospital site, anticoagulant status and category (DOAC versus warfarin) and antiplatelet use. Mean and standard deviation, median and inter-quartile ranges and percentages of baseline demographic were tabulated. Parametric data was compared using ANOVA and Tukey HSD analysis. Non-parametric data was analysed using Kruskal-Wallis test and Mann-Whitney U with Bonferroni adjustment where applicable. Each variable was compared among the three cohorts. For all tests a P value $<0.05$ was considered significant except when Bonferroni adjustment was applied (see text).

\subsection{Role of the funding source}

All funding was in kind support. There was no external funding source for this study. All authors had access to the raw data. The corresponding author had full access to all the data in the study and had final responsibility for the decision to submit for publication.

\section{Results}

\subsection{Patient demographics}


A total of 1240 patients presented to the three sites during the study period. Fourteen patients were excluded from the analyses as they did not undergo operative surgical correction, resulting in a final study cohort of 1226 patients. The median age was 84 years and the majority (71.9\%) were female (Table 1). A total of 145 patients (11.8\%) were on some form of anticoagulation at time of presentation to hospital, with more patients taking a DOAC than warfarin (82 [6.7\%] versus 63 [5.1\%]). Apixaban was the most commonly prescribed DOAC. Antiplatelet use was more common than anticoagulant use, with 366 patients (29.8\%) using some form of anti-platelet agent. Thirteen patients (1.1\%) of patients were on dual therapy, and 714 patients (58.2\%) were not on any anticoagulation or antiplatelet agent. The baseline demographics were not comparable between the three sites (see table 1).

\subsection{Time to surgery}

631 (51.5\%) of patients underwent operative correction within 24 hours. The time to surgery was longer for those on anticoagulation compared to those not on anticoagulation, with those on a DOAC also having a significantly longer time to theatre than those on warfarin (difference in median 16 hours, $\mathrm{P}=0.003$ ). Analysis by site identified a significant difference overall in time to theatre for patients on different anticoagulation agents; post-hoc analysis revealed that this was accounted for by differences in patients taking DOACs to those on warfarin at site A. Whilst time to theatre for warfarin users compared to those not on anticoagulation was significantly different $(\mathrm{P}=0.001)$ the median times were similar (27.9 hrs Vs 23.1 hrs) and likely not clinically relevant. There was no significant difference in time to theatre for patients on an antiplatelet agent compared to those not on any anticoagulant or antiplatelet treatment $(\mathrm{P}=0.616)$ (see table 2$)$.

\subsection{Change in haemoglobin}

In line with documented literature patients on dual anticoagulation and antiplatelet agents had a significantly larger drop in haemoglobin compared to the remainder of the cohort $(\mathrm{P}=0.015 \text {, Table } 3)^{14}$. Evaluation by individual site identified that the only site with differences between the patient groups was site A. There was no difference in change in haemoglobin in DOAC users compared to warfarin users in the total cohort, nor at any of the three individual sites, despite the different peri-operative DOAC protocols.

\subsection{Transfusion requirements}


Despite the higher incidence of bleeding in those on dual antiplatelet and anticoagulant therapy it did not translate into increased transfusion requirement. Comparing all patients on a DOAC to all patients on warfarin, there was no difference in the proportion of patients transfused (table 4). Despite the different peri-operative DOAC protocols across the three sites, no difference in transfusion requirement was identified.

\subsection{Preoperative DOAC Levels}

Thirty-four patients (94\%) on a DOAC at site A had a pre-operative level taken, with the majority of levels being taken within 24 hours of presentation. The rates of DOAC levels were lower at site B (37\%) and C (76.2\%), in keeping with different peri-operative DOAC protocols. Thirteen patients (22.4\% of those who had a DOAC level and $52 \%$ of those who had level within 12 hours)) had a level $\leq 50 \mathrm{ng} / \mathrm{mL}$ within 12 hours of presentation and 24 patients $(41.3 \%$ of those who had a DOAC level) had a level $\leq 50 \mathrm{ng} / \mathrm{mL}$ within 24 hours of presentation. 20 patients (34.4\% of those who had a DOAC level) had a level > $50 \mathrm{ng} / \mathrm{mL}$ in first 24 hours. The mean time to level $\leq 50 \mathrm{ng} / \mathrm{mL}$ was 24.3 hours (SD 14.3 hours) (see table 5).

\section{Discussion}

The results of this study provide valuable insight into the perioperative management of anticoagulation in hip fracture patients. Our study confirms that anticoagulation contributes to surgical delay, as reported by previous literature ${ }^{12-14}$. Within our cohort, $11.8 \%$ were on some form of anticoagulation at time of presentation, which is in line with previously documented data ${ }^{12}$. Regardless of the site and site-specific peri-operative protocol, time to theatre for patients receiving anticoagulation with a DOAC or warfarin was significantly longer than for patients not using these agents.

Despite recommendations that hip fracture patients should be operated on early, only $51.5 \%$ of all patients in our study achieved operation within 24 hours. One reason for this is the specific geographical and technical barriers in Western Australia. This large state spans a total area of 2.5 million $\mathrm{km}^{2}$, with many of the rural, outreach hospitals not being adequately staffed to perform corrective surgery ${ }^{5}$. Hospital B is the registered state trauma centre and services areas $>2.5$ hrs commercial flight away versus Hospital A and C which service areas generally accessible within $1 \mathrm{hr}$ flight time and have lower numbers of inter-hospital referrals ${ }^{6}$. Other factors contributing 
to the delays may have included out of hours presentation, high demands for hospital beds and theatre lists, and patient prioritisation ${ }^{5}$.

We identified similar times to theatre for those on warfarin to those not on anticoagulation at two of the three sites in our study. This is achievable as warfarin can be effectively reversed with vitamin $\mathrm{K}$ and prothrombin concentrates as per standardised protocols ${ }^{15}$. The minor difference between warfarin users and those not on anticoagulation is likely accounted for by the time taken to access antidote therapy, time for Vitamin K effect and laboratory delays for repeat coagulation profiles post antidote administration. Despite all three sites having warfarin reversal protocols the time to surgery for patients on warfarin at site B was considerably higher than their comparator subgroups at site A and C. This likely results from differences in patient catchment zones and baseline demographics.

The delay, cost, interlaboratory variability and difficulty with accessing and interpreting DOAC drug levels are all cited as barriers to their widespread clinical use. However, access to testing was not a limitation in our study. All Western Australian tertiary hospitals have DOAC drug level testing available on site 24 hours a day, within an average time of 90 minutes from specimen receipt in the hospital laboratory, at a cost of \$50 AUD. Given the cost of surgical delay and prolonged inpatient stay, this additional testing cost is relatively minor and could reduce hospital expenditure overall. We recognise, however, that this may be a barrier to incorporation at alternative sites.

The lack of evidence to support a threshold at which major surgery can be considered safe remains a barrier to more widespread utility of DOAC levels. The International Society of Thrombosis and Haemostasis (ISTH) guidelines advise that DOAC levels $>50 \mathrm{ng} / \mathrm{mL}$ are sufficiently high to warrant concerns about bleeding, whereas levels $\leq 30 \mathrm{ng} / \mathrm{mL}$ are not, when interpreted in consideration of time of last dose ${ }^{11}$. Given a significant proportion of patients had levels $<50 \mathrm{ng} / \mathrm{mL}$ at first testing, the expected clearance of these drugs to safe operative levels should be significantly less than the 48-72 hours recommended ahead of major surgery. The ISTH guidelines do not address bleeding risk at levels between 30 and 50ng/mL. We did not identify a difference in bleeding, transfusion requirements or mortality for patients who proceeded to theatre with a level $\leq 50 \mathrm{ng} / \mathrm{mL}$, compared to those with a level $\leq 30 \mathrm{ng} / \mathrm{mL}$, although numbers are small. Further studies are warranted to determine what threshold is appropriate to define a safe level of anticoagulation for hip fracture surgery. 
The frequent finding of low DOAC drug levels soon after presentation should inform future perioperative practice guidelines. Potential reasons for a low level at presentation include poor compliance, delay to presentation and frequent use of low dose anticoagulation in this population. As long as these levels are in keeping with the drug history and are performed on an assay with good performance, then extended surgical delay should be unnecessary. Our results suggest that if DOAC levels were performed regularly on presentation, and if a threshold of $\leq 50 \mathrm{ng} / \mathrm{mL}$ were accepted as safe for surgery, then a significant proportion of patients on DOAC therapy will be able to undergo operative management within 24 hours of presentation.

There are a number of limitations to this study that must be considered when interpreting its findings, primarily related to its retrospective design. We were unable to reliably assess the time of last DOAC dose or actual dose taken, indication for anticoagulation as well as the potential for missed cases of anticoagulation and antiplatelet use. Compounding variables such frailty and other comorbidities were also unknown. Our data did not provide the opportunity to assess for other adverse outcomes associated with surgical delay. The limited cohort numbers prohibit comparison of 30-day mortality between groups. To do so would have required more than 58,000 patients (which based on current incidence rates equates to more than three years of Australian-wide national hip fracture data). Our reported mortality data excludes patients who did not undergo surgical correction.

Nonetheless, the findings of our study raise some questions as to the need to universally prolong the time to hip fracture surgery for DOAC users, and may inform further research in this area. Despite these drugs now being widely accepted and utilised within the clinical arena, knowledge pertaining to specific perioperative management and utility of targeted drug assays is limited. Whilst current guidelines focus on a pharmacokinetic approach this is potentially flawed by patients having variable recall of drug, dosage and time of last administration, reluctance to admit poor compliance and interpatient variability in pharmacodynamics. As we expand our knowledge of calibrated DOAC assays and specific thresholds for bleeding and thrombosis, this approach is likely to change. However, to do so reliably requires more data and specifically data on patients with a bleeding tendency, extremes of body weight, renal and liver dysfunction, polypharmacy and malabsorption ${ }^{16}$.

\section{Conclusion}


In conclusion this is the largest cohort of DOAC treated hip fracture patients to date with baseline DOAC drug levels, objective bleeding and transfusion data. With increasing use of these agents in the hip fracture population and limited data on the role and utility of DOAC drug levels in the perioperative setting, we feel this is an area of need and propose that more baseline DOAC levels could reduce surgical delays. Specifically, collaborative studies evaluating the mortality and safety of surgery at various assay thresholds are required 


\section{References}

1. Australian Institute of Health and Welfare. Hip fracture incidence and hospitalisations in Australia. Canberra. 2018.

2. Simunovic N, Devereaux PJ, Sprague S, Guyatt GH, Schemitsch E, Debeer J et al. Effect of early surgery after hip fracture on mortality and complications: systematic review and meta-analysis. Can Med J Assoc. 2010;182(15):1609. doi:10.1503/cmaj.092220.

3. Orosz GM, Magaziner J, Hannan EL, Morrison RS, Koval K, Gilbert M et al. Association of timing of surgery for hip fracture and patient outcomes. J Am Med Assoc. 2004;291(14):1738. doi:10.1001/jama.291.14.1738.

4. Sheehan KJ, Sobolev B, Villan Villan YF, Guy P. Patient and system factors of time to surgery after hip fracture: a scoping review. Br Med J Open. 2017;7(8):e016939. doi:10.1136/bmjopen-2017016939.

5. Australian and New Zealand guideline for hip fracture care. improving outcomes in hip fracture management of adults. Sydney, Australia: Australian and New Zealand Hip Fracture Registry Steering Group; 2014.

6. ANZHFR Annual Report of Hip Fracture Care 2019. Sydney, Australia: Australian and New Zealand Hip Fracture Registry; 2019.

7. Nicole L Pratt ENR, Gillian E Caughey, Sepehr Shakib and Elizabeth Roughead. Uptake of novel oral anticoagulants in Australia. Med J of Aust. 2016;204(3):104-5. doi:10.5694/mja15.01000. 8. Faraoni D, Levy JH, Albaladejo P, Samama CM. Updates in the perioperative and emergency management of non-vitamin K antagonist oral anticoagulants. Crit Care. 2015;19:203. doi:10.1186/s13054-015-0930-9.

9. Heidbuchel H, Verhamme P, Alings M, Antz M, Diener HC, Hacke W et al. Updated European Heart Rhythm Association practical guide on the use of non-vitamin K antagonist anticoagulants in patients with non-valvular atrial fibrillation. Europace. 2015;17(10):1467-507. doi:10.1093/europace/euv309. 
10. Albaladejo P, Bonhomme F, Blais N, Collet JP, Faraoni D, Fontana P et al. Management of direct oral anticoagulants in patients undergoing elective surgeries and invasive procedures: Updated guidelines from the French Working Group on Perioperative Hemostasis (GIHP) September 2015. Anaes Crit Care Pain Med. 2017;36(1):73-6. doi:10.1016/j.accpm.2016.09.002.

11. Levy JH, Ageno W, Chan NC, Crowther M, Verhamme P, Weitz JI. When and how to use antidotes for the reversal of direct oral anticoagulants: guidance from the SSC of the ISTH. J Thrombosis Haemostasis. 2016;14(3):623-7. doi:10.1111/jth.13227.

12. Tran T, Delluc A, de Wit C, Petrcich W, Le Gal G, Carrier M. The impact of oral anticoagulation on time to surgery in patients hospitalized with hip fracture. Thrombosis Res. 2015;136(5):962-5. doi:10.1016/j.thromres.2015.09.017.

13. Ranhoff AH, Martinsen MI, Holvik K, Solheim LF. Use of warfarin is associated with delay in surgery for hip fracture in older patients. Hosp Prac. 2011;39(1):37-40. doi:10.3810/hp.2011.02.372. 14. Schermann H, Gurel R, Gold A, Maman E, Dolkart O, Steinberg EL et al. Safety of urgent hip fracture surgery protocol under influence of direct oral anticoagulation medications. Injury. 2019;50(2):398-402. doi:10.1016/j.injury.2018.10.033.

15. Tran HA, Chunilal SD, Harper PL, Tran H, Wood EM, Gallus AS. An update of consensus guidelines for warfarin reversal. Med J Aust. 2013;198(4):198-9. doi:10.5694/mja12.10614.

16. Douxfils J, Ageno W, Samama C-M, Lessire S, ten Cate H, Verhamme P et al. Laboratory testing in patients treated with direct oral anticoagulants: a practical guide for clinicians. J Thrombosis Haemostasis. 2018;16(2):209-19. doi:10.1111/jth.13912. 
Table 1: Baseline demographics of the cohort.

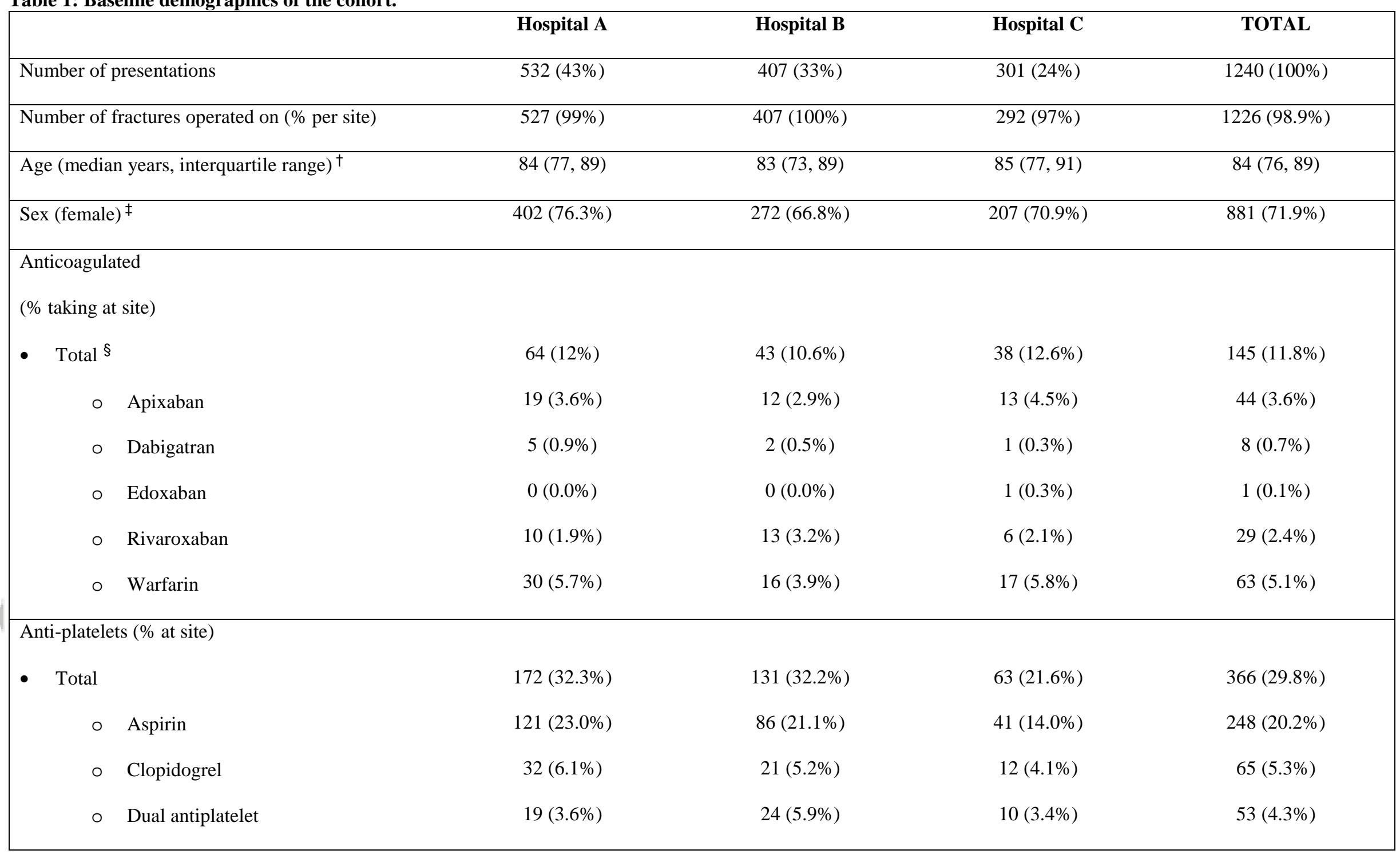




\begin{tabular}{|c|c|c|c|c|}
\hline $\begin{array}{l}\text { Number of patients on dual anticoagulation and } \\
\text { antiplatelet agents }\end{array}$ & 6 (1.1\%) & $6(1.5 \%)$ & $1(0.3 \%)$ & $13(1 \%)$ \\
\hline $\begin{array}{l}\text { Number of patients not on any anticoagulation or } \\
\text { antiplatelet agent }\end{array}$ & 297 (56.3\%) & 227 (55.8\%) & 190 (65.1\%) & 714 (58.2\%) \\
\hline $\begin{array}{l}{ }^{\dagger} \text { A Kruskal Wallis test identified a significant diff } \\
{ }^{\ddagger} \text { Chi square analysis identified a significant differ } \\
{ }^{\S} \text { Chi square analysis identified a significant differ }\end{array}$ & $\begin{array}{l}\text { nedian age betv } \\
\text { centage of fem } \\
\text { centage of pati }\end{array}$ & $\begin{array}{l}\text { sites }\left(\chi^{2}=11.0,\right. \\
\text { le }\left(\chi^{2}=10.3, \mathrm{df}=\right. \\
\text { lated at each sit }\end{array}$ & $=8, \mathrm{P}=0.02)$ & \\
\hline
\end{tabular}


Table 2: Time to theatre (hours)

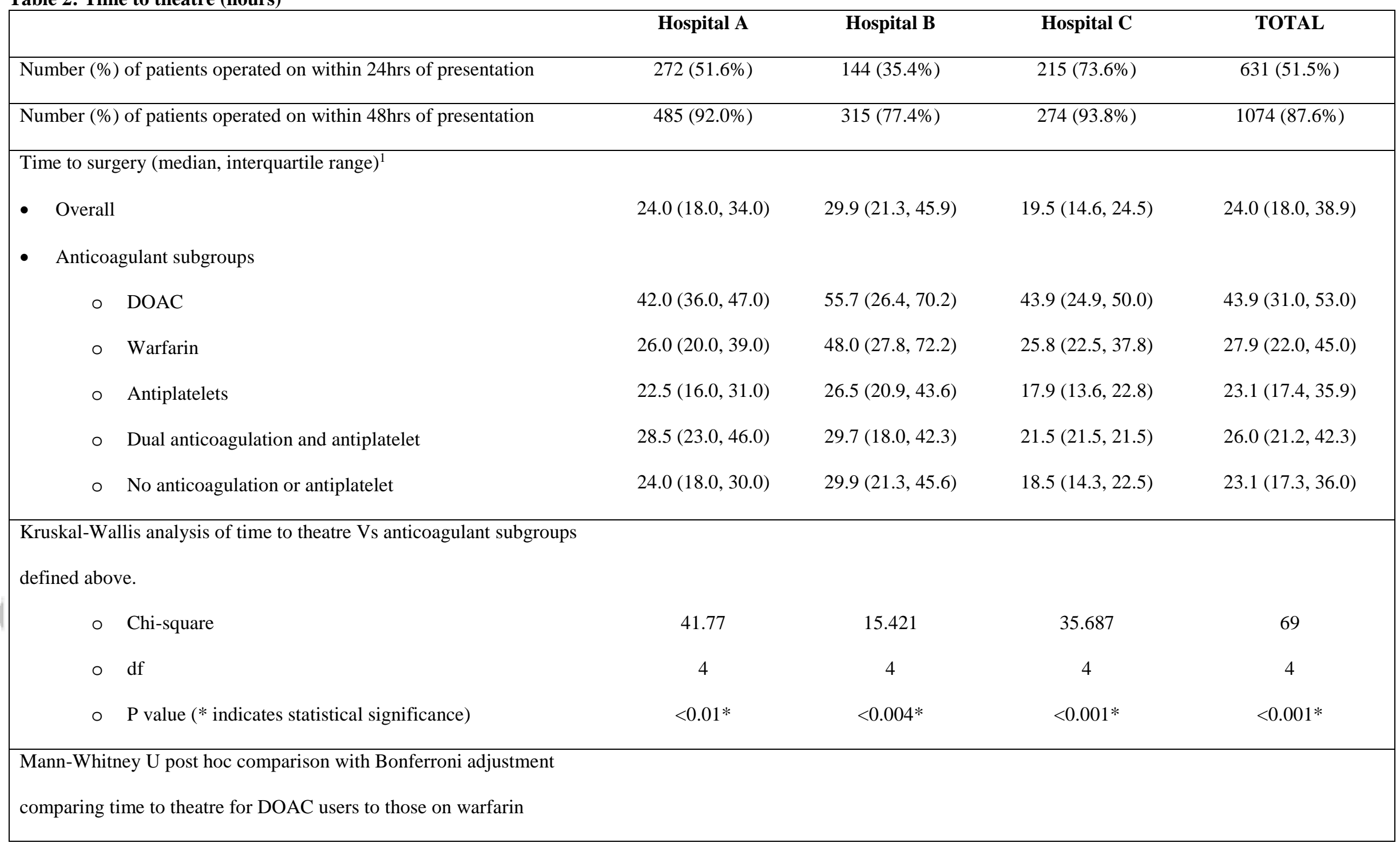

This article is protected by copyright. All rights reserved. 


\begin{tabular}{|llllll|}
\hline $\mathrm{O}$ & Mann-Whitney U & 216.000 & 161.5 & 126.0 & 1516.5 \\
$\mathrm{O}$ & $\mathrm{Z}$ score & -3.158 & 0.197 & -1.728 & -2.985 \\
$\mathrm{O}$ & P value $(*$ indicates statistical significance, $\mathrm{p}<0.025)$ & $0.002^{*}$ & 0.844 & 0.084 & $0.003^{*}$ \\
\hline
\end{tabular}


Table 3: Change in haemoglobin $(\mathrm{g} / \mathrm{L})$

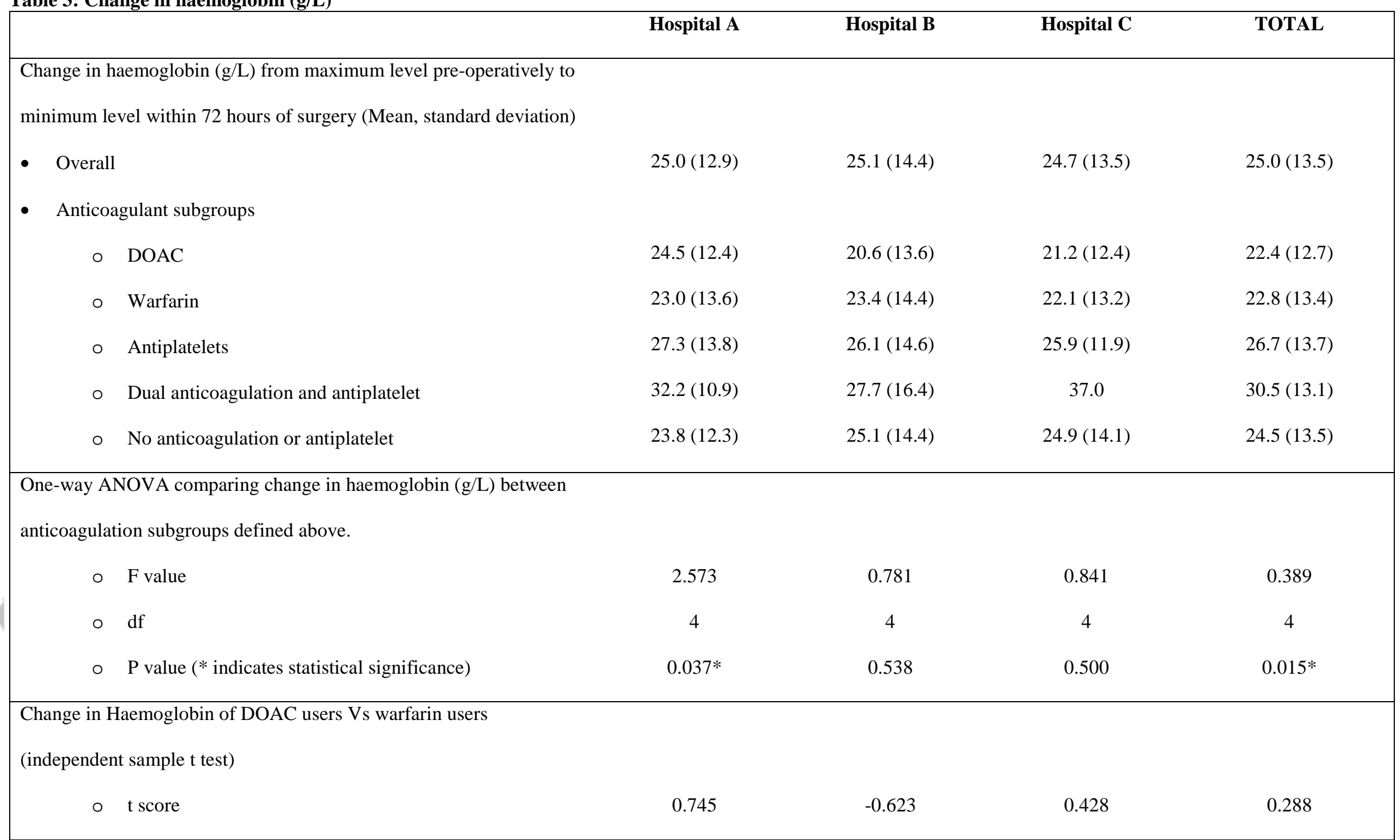




\begin{tabular}{|c|c|c|c|c|}
\hline $0 \quad \mathrm{df}$ & 62 & 38 & 35 & 139 \\
\hline $\mathrm{O} \quad \mathrm{P}$ value & 0.459 & 0.537 & 0.671 & 0.774 \\
\hline
\end{tabular}


Table 4: Transfusion Requirements

Hospital A

Number of patients transfused packed red blood cell units 2 days pre-

operatively to 3 days post-operatively (\% per anticoagulant subgroup

defined above per site)

- Total

O DOAC

o Warfarin

o Antiplatelets

o Dual anticoagulation and antiplatelet

o No anticoagulation or antiplatelet

$94(17.8 \%)$

$4(11.8 \%)$

$5(16.7 \%)$

$41(23.4 \%)$

$2(33.3 \%)$

$42(14.1 \%)$
Hospital B

19.901

4.174

25.083

o Chi-square

$0 \quad \mathrm{df}$

o P value (* indicates statistical significance)

$0.048^{*}$

4

$0.001 *$

0.383

Kruskal-Wallis analysis of number of patients requiring PRBC

transfusion in DOAC Vs warfarin users

o Chi-square

0.917

0.089

0.955

0.397 


\begin{tabular}{|llcccc|}
\hline 0 & $\mathrm{df}$ & 1 & 1 & 1 & 1 \\
$\mathrm{O}$ & P value & 1.000 & 0.137 & 1.00 & 0.425 \\
\hline
\end{tabular}


Table 5: Pre-operative DOAC levels

\begin{tabular}{|c|c|c|c|c|}
\hline & Hospital A & Hospital B & Hospital C & TOTAL \\
\hline Number of Patients on a DOAC (\% of cohort) & $34(6.5 \%)$ & $27(6.6 \%)$ & $21(7.2 \%)$ & $82(6.7 \%)$ \\
\hline \multicolumn{5}{|l|}{ Number of patients who had a DOAC level prior to surgery } \\
\hline o Total (\% of total) & 32 (94\%) & $10(37 \%)$ & $16(76.2 \%)$ & $58(70.7 \%)$ \\
\hline \multicolumn{5}{|l|}{ Of those who had a level: } \\
\hline o Within 12 hours of presentation (\% of total) & $15(46.8 \%)$ & $4(40 \%)$ & $6(37.5 \%)$ & $25(43 \%)$ \\
\hline o Within 24 hours of presentation (\% of total) & $29(90.6 \%)$ & $6(60 \%)$ & $11(68.5 \%)$ & $46(79.3 \%)$ \\
\hline $\begin{array}{l}\text { Number of patients with DOAC level } \leq 30 \mathrm{ng} / \mathrm{mL} \text { within } 12 \text { hours of } \\
\text { presentation (\% of patients who had a level in first } 12 \text { hours) }\end{array}$ & $2(13.3 \%)$ & $3(75 \%)$ & $1(16.7 \%)$ & $6(24 \%)$ \\
\hline $\begin{array}{l}\text { Number of patients with DOAC level }>30 \mathrm{ng} / \mathrm{mL} \text { and } \leq 50 \mathrm{ng} / \mathrm{mL} \\
\text { within } 12 \text { hours of presentation (\% of patients who had a level in first } \\
12 \text { hours) }\end{array}$ & $5(33.3 \%)$ & $1(25 \%)$ & $1(16.7 \%)$ & $7(28 \%)$ \\
\hline $\begin{array}{l}\text { Number of patients with DOAC level }>50 \mathrm{ng} / \mathrm{mL} \text { within } 12 \text { hours of } \\
\text { presentation (\% of patients who had a level in first } 12 \text { hours) }\end{array}$ & $8(53.3 \%)$ & $0(0 \%)$ & $4(66.6 \%)$ & $12(48 \%)$ \\
\hline $\begin{array}{l}\text { Number of patients with DOAC level } \leq 30 \mathrm{ng} / \mathrm{mL} \text { within } 24 \text { hours of } \\
\text { presentation (\% of patients who had a level in first } 24 \text { hours) }\end{array}$ & $10(34.5 \%)$ & $5(83.3 \%)$ & $3(27.3 \%)$ & $18(39.1 \%)$ \\
\hline
\end{tabular}

This article is protected by copyright. All rights reserved. 


\begin{tabular}{|c|c|c|c|c|}
\hline $\begin{array}{l}\text { Number of patients with DOAC level }>30 \mathrm{ng} / \mathrm{mL} \text { and } \leq 50 \mathrm{ng} / \mathrm{mL} \\
\text { within } 24 \text { hours of presentation (\% of patients who had a level in first } \\
24 \text { hours) }\end{array}$ & $5(17.2 \%)$ & $1(16.7 \%)$ & $2(18.2 \%)$ & $8(17.3 \%)$ \\
\hline $\begin{array}{l}\text { Number of patients with DOAC level > } 50 \mathrm{ng} / \mathrm{mL} \text { within } 24 \text { hours of } \\
\text { presentation (\% of patients who had a level in first } 24 \text { hours) }\end{array}$ & $14(48.3 \%)$ & $0(0 \%)$ & $6(54.5 \%)$ & $20(43.5 \%)$ \\
\hline Mean time to level $\leq 50 \mathrm{ng} / \mathrm{mL}$ in hours (std dev) & $24(15.2)$ & $21(15.3)$ & $26.9(12.2)$ & $24.3(14.3)$ \\
\hline
\end{tabular}

